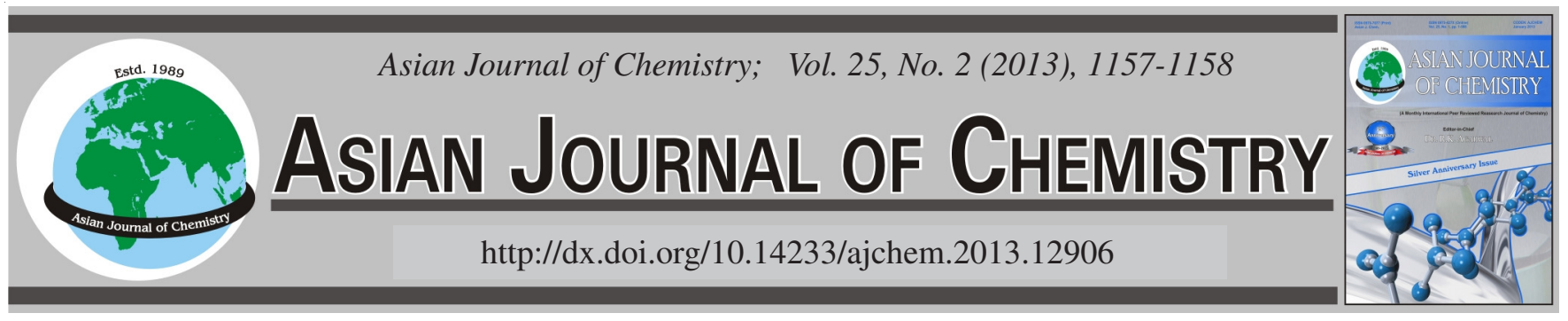

NOTE

\title{
Synthesis and Crystal Structure of Aminium 2-(Carbonyl)-3,4,5,6-tetrabromobenzoate 3,4,5,6-Tetrabromobenzene-1,2-dioic Acid Propanone Monosolvate
}

\section{JIAN Li}

Department of Chemistry and Chemical Engineering, Weifang University, Weifang 261061, P.R. China

Corresponding author: Tel: +86 536 8877561; E-mail: ljwfu@163.com

\begin{abstract}
The compound aminium 2-(carbonyl)-3,4,5,6-tetrabromobenzoate 3,4,5,6-tetrabromobenzene-1,2-dioic acid propanone monosolvate $\left(\mathrm{C}_{19} \mathrm{H}_{13} \mathrm{Br}_{8} \mathrm{NO}_{9}, \mathrm{M}_{\mathrm{r}}=1038.58\right)$ was synthesized and characterized by single crystal X-ray diffraction. The crystal belongs to monoclinic, space group $C 2 / \mathrm{c}$, with $\mathrm{a}=23.870(2), \mathrm{b}=10.8790(10), \mathrm{c}=12.2069(13) \AA, \beta=107.186(2)^{\circ}, \mathrm{V}=3028.4(5) \AA^{3}, \mathrm{Z}=4, \mathrm{D}_{\mathrm{c}}=2.278 \mathrm{~g} / \mathrm{cm}^{3}$, $\lambda=0.71073 \AA, \mu\left(M_{o K}\right)=10.638 \mathrm{~mm}^{-1}, \mathrm{~F}_{(000)}=1944$. The final refinement gave $\mathrm{R}=0.1176, w \mathrm{R}\left(\mathrm{F}^{2}\right)=0.2719$ for 7,196 observed reflections with $\mathrm{I}>2 \sigma(\mathrm{I})$. The asymmetric unit of the title compound contains one aminium cation, one 2-(carbonyl)-3,4,5,6tetrabromobenzoate anion, one 3,4,5,6-tetrabromobenzene-1,2-dioic acid molecule and one propanone molecule. In the anions, the mean planes of the carbonyl and carboxylate groups form dihedral angles of $68.1(3)$ and $62.7(3)^{\circ}$, respectively with the benzene ring. In the crystal, intermolecular $\mathrm{N}-\mathrm{H} \cdots \mathrm{O}, \mathrm{N}-\mathrm{H} \cdots \mathrm{Br}$ and $\mathrm{O}-\mathrm{H} \cdots \mathrm{O}$ hydrogen bonds connect the components of the structure to form a two-dimensional network.
\end{abstract}

Key Words: Aminium 2-(carbonyl)-3,4,5,6-tetrabromobenzoate, Monosolvate, Synthesis, Crystal structure.

Tetrabromphthalimide and its derivatives have been found to be useful flame retardants in polyesters, e.g., polybutylene terephthalate and other resin formulations ${ }^{1}$. Several intermediates of them have been synthesized in the previous work ${ }^{2-4}$. In present work, the reaction of tetrabromophthalic anhydride and amine in propanone is expected to form 4,5,6,7tetrabromoisoindoline-1,3-dione, but instead formed aminium 2-(carbonyl)-3,4,5,6-tetrabromobenzoate 3,4,5,6-tetrabromobenzene-1,2-dioic acid propanone monosolvate. This may have happened because of the presence of water for the reaction. In this paper, the synthesis and the crystal structure of aminium 2-(carbonyl)-3,4,5,6-tetrabromobenzoate 3,4,5,6-tetrabromobenzene-1,2-dioic acid propanone monosolvate is reported.

Synthesis of the aminium 2-(carbonyl)-3,4,5,6-tetrabromobenzoate 3,4,5,6-tetrabromobenzene-1,2-dioic acid propanone monosolvate: All the reagents were of AR grade and used without further purification. A mixture of tetrabromophthalic anhydride (4.64 g, $0.01 \mathrm{~mol})$ and ammonia water $(25 \%)(0.68 \mathrm{~g}, 0.01 \mathrm{~mol})$ in propanone $(15 \mathrm{~mL})$ was refluxed for $0.5 \mathrm{~h}$. And then the solution was kept at room temperature for $9 \mathrm{~d}$. Natural evaporation gave colourless single crystals of aminium 2-(carbonyl)-3,4,5,6-tetrabromobenzoate 3,4,5,6tetrabromobenzene-1,2-dioic acid propanone monosolvate, suitable for X-ray analysis.
Data collection and structure determination: A selected crystal of the title compound was mounted on a SMART CCD diffractometer. The reflection data were measured at $298 \mathrm{~K}$, using a graphite monochromator $\operatorname{MoK}_{\alpha}(\lambda=0.71073 \AA)$ radiation with an $\omega-2 \theta$ scan mode. The total reflections were 7,196 with 2,629 independent ones $\left(R_{\text {int }}=0.2158\right)$, of which 175 were observed with $\mathrm{I}>2 \sigma(\mathrm{I})$. Intensities were corrected for Lorentz and polarization effects and empirical absorption and all data were corrected using $\mathrm{SADABB}^{5}$ program.

The structure was solved by direct methods using SHELXS $-97^{6}$ program. All the non-hydrogen atoms were refined on $\mathrm{F}^{2}$ anisotropically by full-matrix least squares method. All hydrogen atoms were placed in the geometrically calculated positions. The contributions of these hydrogen atoms were included in the structurefactor calculations. The atomic scattering factors and anomalous dispersion corrections were taken from International Table for X-ray crystallography ${ }^{7}$. The final least-square cycle gave $\mathrm{R}=0.1176$ and $\omega \mathrm{R}=0.2719$ $\left(\mathrm{w}=1 /\left[\sigma^{2}\left(\mathrm{Fo}^{2}\right)+(0.1592 \mathrm{P})^{2}+0.0000 \mathrm{P}\right]\right.$, where $\mathrm{P}=\left(\mathrm{Fo}^{2}+\right.$ $\left.\left.2 \mathrm{Fc}^{2}\right) / 3\right) . \mathrm{S}=1.061,(\Delta \rho)_{\min }=-3.125$ and $(\Delta \rho)_{\max }=4.119 \mathrm{e} / \AA^{3}$. CIF file containing complete information on the studied structure was deposited with CCDC, deposition number 824533 and is freely available upon request from the following web site: www.ccdc.cam.ac.uk/data_request/cif 
The selected bond distances and bond angles are listed in Table-1. A displacement ellipsoid plot with atomic numbering scheme is shown in Fig. 1 and a perspective mLew of the crystal packing in the unit cell is shown in Fig. 2. Hydrogen bond schemes $\left(\AA,^{\circ}\right)$ are listed in Table- 2 .

\section{TABLE-1}

SELECTED BOND LENGTHS $(\AA)$ AND BOND ANGLES $\left({ }^{\circ}\right)$

\begin{tabular}{cccc}
\hline Bond & Length $(\AA)$ & Bond & Angle $\left(^{\circ}\right)$ \\
\hline $\mathrm{Br}(1)-\mathrm{C}(5)$ & $1.85(2)$ & $\mathrm{O}(2)-\mathrm{C}(1)-\mathrm{O}(1)$ & $124(2)$ \\
$\mathrm{Br}(2)-\mathrm{C}(6)$ & $1.91(2)$ & $\mathrm{O}(2)-\mathrm{C}(1)-\mathrm{C}(3)$ & $115(2)$ \\
$\mathrm{Br}(3)-\mathrm{C}(7)$ & $1.89(2)$ & $\mathrm{O}(1)-\mathrm{C}(1)-\mathrm{C}(3)$ & $120.5(18)$ \\
$\mathrm{Br}(4)-\mathrm{C}(8)$ & $1.89(2)$ & $\mathrm{O}(4)-\mathrm{C}(2)-\mathrm{O}(3)$ & $126(2)$ \\
$\mathrm{O}(1)-\mathrm{C}(1)$ & $1.27(3)$ & $\mathrm{O}(4)-\mathrm{C}(2)-\mathrm{C}(4)$ & $119(2)$ \\
$\mathrm{O}(2)-\mathrm{C}(1)$ & $1.26(2)$ & $\mathrm{O}(3)-\mathrm{C}(2)-\mathrm{C}(4)$ & $115(2)$ \\
$\mathrm{O}(3)-\mathrm{C}(2)$ & $1.27(3)$ & $\mathrm{C}(8)-\mathrm{C}(3)-\mathrm{C}(1)$ & $120(2)$ \\
$\mathrm{O}(4)-\mathrm{C}(2)$ & $1.20(3)$ & $\mathrm{C}(5)-\mathrm{C}(4)-\mathrm{C}(2)$ & $116(2)$ \\
$\mathrm{O}(5)-\mathrm{C}(9)$ & $1.24(4)$ & $\mathrm{C}(4)-\mathrm{C}(3)-\mathrm{C}(1)$ & $119.5(18)$ \\
- & - & $\mathrm{C}(3)-\mathrm{C}(4)-\mathrm{C}(2)$ & $123(2)$ \\
\hline
\end{tabular}
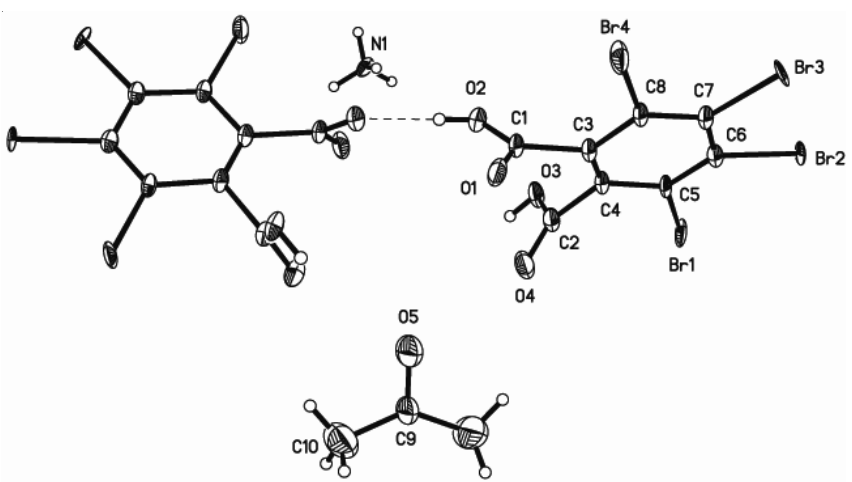

Fig. 1. Molecular structure with atomic numbering scheme

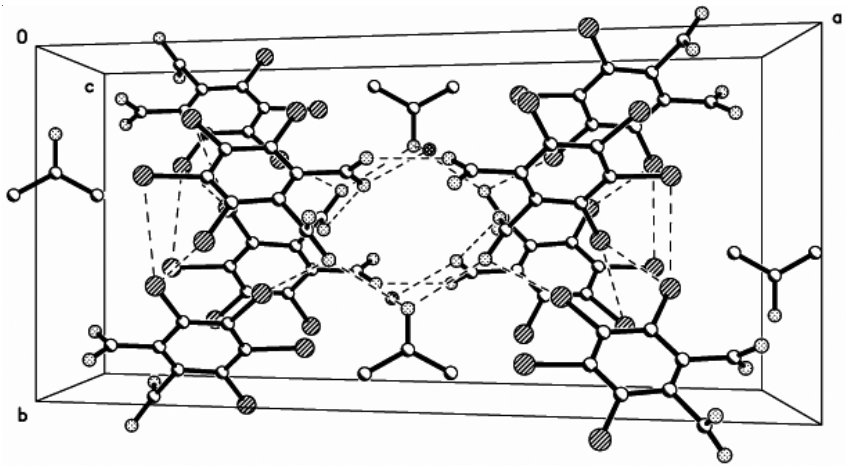

Fig. 2. View of crystal packing down the c-axis
TABLE-2

HYDROGEN BOND SCHEMES $\left(\AA,{ }^{\circ}\right)$

\begin{tabular}{|c|c|c|c|c|}
\hline D-H...A & D-H & H...A & D-A & D-H...A \\
\hline N1-H1A...O1 & 0.90 & 1.86 & 2.76 & 176 \\
\hline N1-H1B...O5 & 0.90 & 1.93 & 2.83 & 172 \\
\hline N1-H1C...O3 $3^{b}$ & 0.90 & 2.33 & 3.19 & 161 \\
\hline N1-H1D...Br2 & 0.90 & 2.91 & 3.50 & 124 \\
\hline $\mathrm{O} 2-\mathrm{H} 2 \ldots 2^{\mathrm{c}}$ & 0.82 & 1.69 & 2.50 & 171 \\
\hline $\mathrm{O} 3-\mathrm{H} 3 \ldots \mathrm{O}^{\mathrm{d}}$ & 0.82 & 1.82 & 2.61 & 159 \\
\hline
\end{tabular}

Symmetry codes: (a) x, 1-y, -1/2 + z, (b) 1/2-x, 1/2-y, -z (c) 1-x, y, 1/2$\mathrm{z}(\mathrm{d})-1 / 2+\mathrm{x}, 1 / 2-\mathrm{y},-1 / 2+\mathrm{z}$.

The asymmetric unit of the title compound contains one aminium cation, one 2-(carbonyl)-3,4,5,6-tetrabromobenzoate anion, one 3,4,5,6-tetrabromobenzene-1,2-dioic acid molecule and one propanone molecule (Fig. 1). The bond lengths and angles are in agreement with those in propane-1,3-diaminium bis [3,4,5,6-tetrabromo-2-(methoxycarbonyl)benzoate] water monosolvate ${ }^{2}$, cyclohexanaminium 3,4,5,6-tetrachloro-2(methoxycarbonyl)benzoate ${ }^{3}$ and ethylammonium 2(methoxycarbonyl)-3,4,5,6-tetrabromobenzoate methanol solvate $^{4}$. In the anions, the mean planes of the carbonyl and carboxylate groups form dihedral angles of 68.1(3) and $62.7(3)^{\circ}$, respectively with the benzene ring. In the crystal, intermolecular $\mathrm{N}-\mathrm{H} \cdots \mathrm{O}, \mathrm{N}-\mathrm{H} \cdots \mathrm{Br}$ and $\mathrm{O}-\mathrm{H} \cdots \mathrm{O}$ hydrogen bonds connect the components of the structure to form a two-dimensional network (Fig. 2 and Table-2).

\section{ACKNOWLEDGEMENTS}

This work was supported by Shandong Provincial Natural Science Foundation, China (No. ZR2009BL027).

\section{REFERENCES}

1. J.W. Roos and R.M. Moore, US Patent, 5076970 (1991).

2. Z.P. Liang and J. Li, Asian J. Chem., 25, 780 (2013).

3. J. Li, Acta Cryst., E67, o842 (2011).

4. J. Li, Acta Cryst., E67, o200 (2011).

5. G.M. Sheldrick, SADABS, Program for Empirical Absorption Correction of Area Detector Data, University of Gottingen, Germany (1996).

6. G.M. Sheldrick, SHELXTL V 5.1 Software Reference Manual, Bruker AXS, Inc., Madison, Wisconsin, USA (1997).

7. Siemens, SMART and SAINT, Area Detector Control and Integration Software, Siemens Analytical X-Ray Systems, Inc., Madison, Wisconsin, USA (1996). 